\title{
Se os pés habitassem os sapatos
}

\section{Sebastiana Fadda}

\section{Osenhor Ibrahim \\ e as flores do Corão, \\ de Eric-Emmanuel \\ Schmitt,}

enc. João Maria André,

Teatro Académico de Gil.

Vicente \& Camaleão

Associação Cultural, 2007

(Hélder Wasterlain

e Rui Damasceno ),

fot. Rita Carmo.
Mais informações em www.eric-emmanuel-

schmitt.com/.

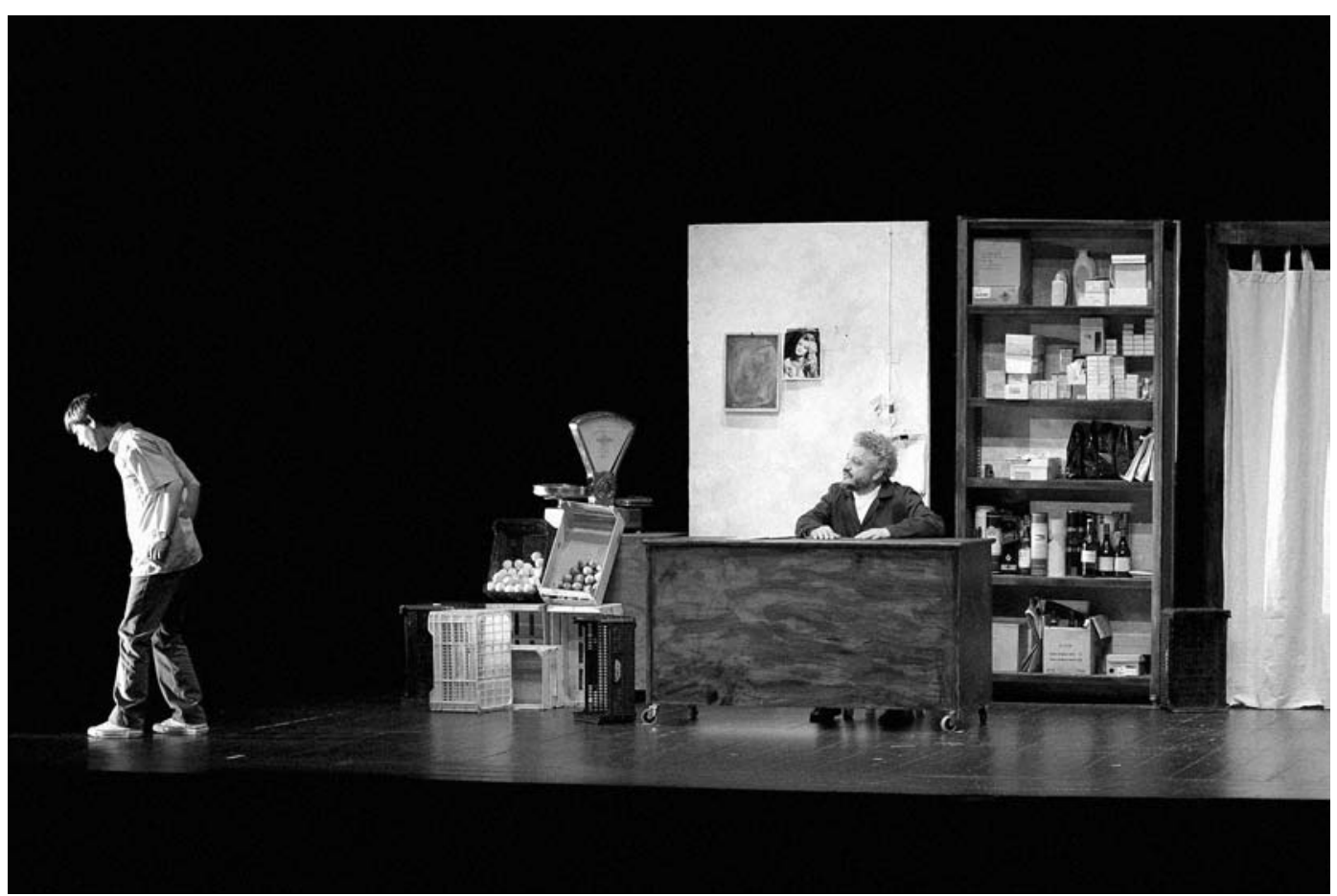

Titulo: $O$ senhor Ibrahim e as flores do Corão (1999). Autor: Eric-Emmanuel Schmitt. Tradução e adaptação: João Maria André (a partir da versão dramatúrgica para dois actores de Ernesto Caballero) . Encenação: João Maria André. Assistente de encenação: Helena Faria. Cenografia, adereços de cena e design gráfico: Miguel Dominguez. Figurinos e adereços: Andrea Inocêncio. Música original: João Lóio. Desenho de luz: Nuno Meira. Teatro Académico de Gil Vicente \&t Camaleão Associação Cultural. Local e data de estreia: Teatro Académico de Gil Vicente, Coimbra, 5 de Julho de 2007.

Dramaturgo, romancista, guionista, cineasta e tradutor de sucesso internacional, Eric-Emmanuel Schmitt estreouse em 1991 com La nuit de Valogne, a que se seguiram muitas outras peças, pluripremiadas e representadas em muitas línguas e em muitos paises: Le visiteur (1993), Golden Joe (1995), Variations énigmatiques (1996), Le libertin e Milarepa (ambas de 1997), Frédérick ou le boulevard du crime (1998), Hôtel des deux mondes (1999), Monsieur Ibrahim et les fleurs du Coran (1999), Oscar et la dame rose (2003), Petits crimes conjugaux (2003), Mes Evangiles: L'Evangile selon Pilate e La Nuit des oliviers (ambas de 2004), La tectonique des sentiments (2005) e as peças curtas em um acto L'école du diable (1996), Le bâillon (1999), Mille et un jour (2000)' ${ }^{1}$. Algumas delas convocam mitos literários (La nuit de Valogne é uma releitura do mito de Dom João e Mes Evangiles reinterpreta episódios do Novo Testamento) e figuras da história da cultura (em Le libertin surge Diderot e em Le visiteur Freud). Sobre temas de candente actualidade verte o "Ciclo do Invisivel", que, servindo-se das modalidades dramática e/ou narrativa e cinematográfica, propõe a convivência pacifica inter-religiosa, num mundo em que as religiões são por vezes pretexto para intolerâncias maiores e dissimuladas (Milarepa convoca o budismo, Monsieur Ibrahim o islamismo sufi, Oscar et la dame rose o cristianismo, L'enfant de Noé, de 2004, o judaísmo).

É quase exclusivamente como dramaturgo que o autor é conhecido também em Portugal, onde já teve visibilidade graças a várias produções, nacionais e internacionais, que foram levadas à cena em vários palcos do país: $A$ mordaça (Teatro Plástico, 2000), A visita (Novo Grupo/Teatro Aberto, 2001), Variações enigmáticas (Teatro S. Luiz, 2002; Seiva Trupe, 2004), Hotel dos dois mundos (Teatro Nacional D. Maria II-Cristina Carvalhal Produções Artísticas, 2006), Pequenos crimes conjugais (Teatro Nacional D. Maria II, 2007), O senhor Ibrahim e as flores do Corão (Uróc Teatro, 2007; CAC-TAGV, 2007), Óscar e a senhora cor-de-rosa (Teatro Nacional D. Maria II, 2008)².

A produção portuguesa de 0 senhor Ibrahim e as flores do Corão (pela Camaleão Associação Cultural e Teatro Académico de Gil Vicente) foi apresentada em Coimbra no início de Julho de 2007 e em Lisboa, no Instituto Franco- 


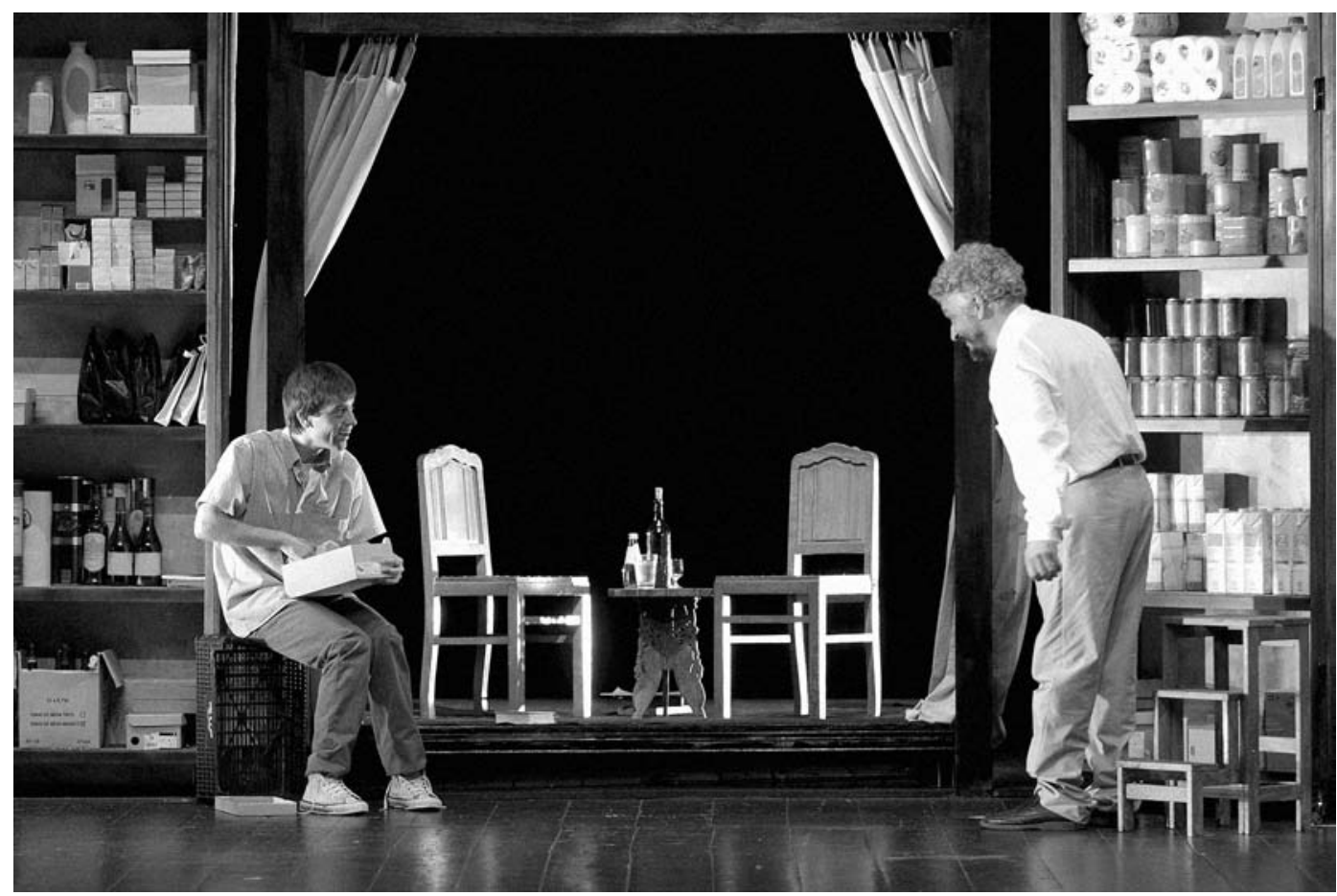

Português, em finais de Março de 2008. Se não fosse pela forma dialogada, poderia pertencer ao género do conto de iniciação (pelo seu enredo) de atmosfera fantástica (pela incidência da imaginação na transfiguração do real e até pelas insinuações semânticas da onomástica e da toponomástica). A acção passa-se na Rue Bleue (Rua Azul), onde o velho Ibrahim (forma árabe do hebraico Abraão, muçulmano sufi, literalmente "pai duma multidão") tem uma mercearia. 0 jovem adolescente Moisés (judeu, literalmente "aquele que foi salvo das águas") vai à mercearia desse homem roubar latas de conservas. 0 acanhamento do rapaz encontra a benevolência do velho, e o mútuo desconhecimento consegue ser suplantado pela familiaridade. 0 diálogo envolve-os progressivamente, e da conversa genérica passa-se à forma do intercâmbio intergeracional e, deste, a uma confidência e cumplicidade que, devagar, permitem a construção duma relação feita de afecto e respeito. Poder-se-ia considerar uma relação parental por escolha deliberada.

Do ponto de vista dramatúrgico, o público presencia as trocas de informações e conversas que vão desde episódios do quotidiano a verdades insondáveis. Mencionase uma passagem da vedeta Brigitte Bardot pela loja, ou então a promessa de redenção da carne pelo sexo mercenário na Rue du Paradis (Rua do Paraíso). Mas há também os pequenos gestos. Como o ensinamento do sorriso, das boas maneiras e da boa disposição, bem como a distinção entre ricos e pobres, cujo reconhecimento é efectuado a partir da avaliação do seu lixo. A gorjeta para o rapaz quando vai fazer as compras e que é acrescentada por Ibrahim à conta que o jovem deverá apresentar ao pai. A oferta dum par de sapatos, como sinal de ingresso e admissão no mundo dos adultos. Ou ainda o convite para beber no espaço privado, numa comunhão ritual entre homens. Outras vezes basta a imaginação para viajarem num hipotético carro rumo às diferentes civilizações, ou então partilhar o espaço mistico da dança cósmica dos dervixes rodopiantes, que assim procuram libertar o coração espiritual, prisioneiro dos seus remanescentes invólucros físicos. Porque todos os homens precisam de um templo onde rezar: nem que seja o do seu próprio corpo, ou o da interioridade.

Acerca de Ibrahim, fechado como aquele livro sagrado que tem na loja, permanece um certo mistério. Fleumático e de verbo comedido, por ele falam sobretudo as suas acções. Quanto ao jovem, saber-se-á que foi abandonado pela mãe, a seguir será pelo pai, que morrerá suicida. Mas quando ainda estava em vida, o pai já tinha abandonado o filho a si próprio. É por isso que o comerciante, que se apercebeu da solidão de Moisés, por ele chamado Momo, acaba por ocupar um enorme lugar vazio na afectividade do rapaz. Será Ibrahim que acalmará 


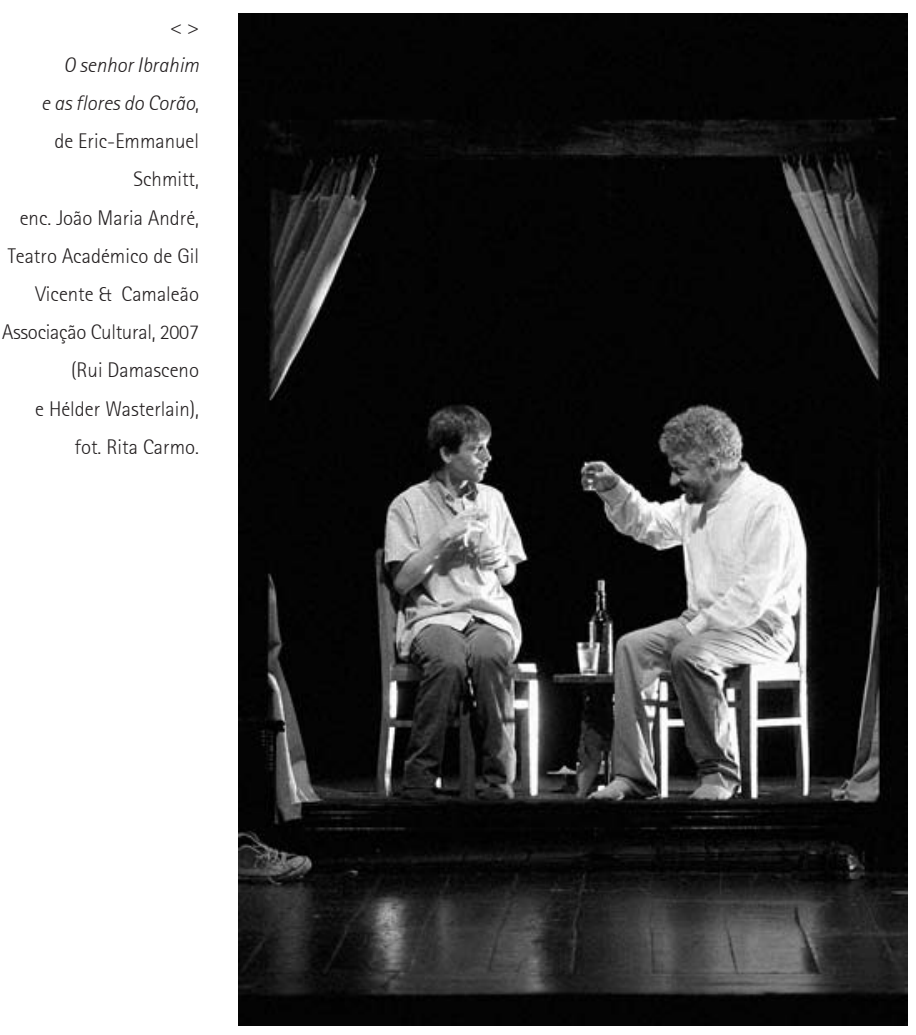

ressentimentos e sentimentos de culpa pelo dúplice abandono: o pai biológico tinha a sua própria tragédia de desamparo, pois sobrevivera aos campos de extermínio nazi enquanto os pais dele morreram no massacre. E será ainda o velho que permitirá a reconciliação interior com a reaparecida mãe. Que uma aludida adopção passe a ter viabilidade legal é apenas um pormenor formal, pois de facto ela já está em vigor, na prática militante do quotidiano.

Na verdade, é pelo diálogo que, neste palco, mesmo acontecendo pouca coisa, se passa muito mais do que é dito: o encontro entre dois seres humanos de culturas diferentes e que vivem normalmente de costas viradas uma para a outra; a partilha da intimidade, de que o tratamento do rapaz pelo sobrenome Momo é um prenúncio desde o início; a aprendizagem da

comunicação e a iniciação à vida, por parte do rapaz; a transmissão do saber, da memória e da vivência, por parte do velho.

0 livro referido no título da peça, o Corão, é antes de mais o símbolo do inatingivel, do enigma supremo e absoluto. As flores secas que ai estão guardadas representam a vida encerrada no âmago do mistério, bem como os rastos efémeros deixados pelos transeuntes de passagem. Por isso ler o livro não serve, estando o seu código ininteligivel para os demais. No entanto, há pequenas frestas luminosas que apontam caminhos. Para se aprender, fala-se com as pessoas. Para se descobrir o segredo da felicidade, tem que se viver lentamente. Tendo presente a pequenez humana (de que os cheiros corporais são o memorando) e a sua miséria (cada homem só tem duas coisas: a sua cama e os seus sapatos). Contudo, se os pés habitassem os sapatos, haveria consciência do seu lugar no espaço, bem como da sua ligação com o pó da terra que pisam. Para estabilidade e orientação num universo sem norte.

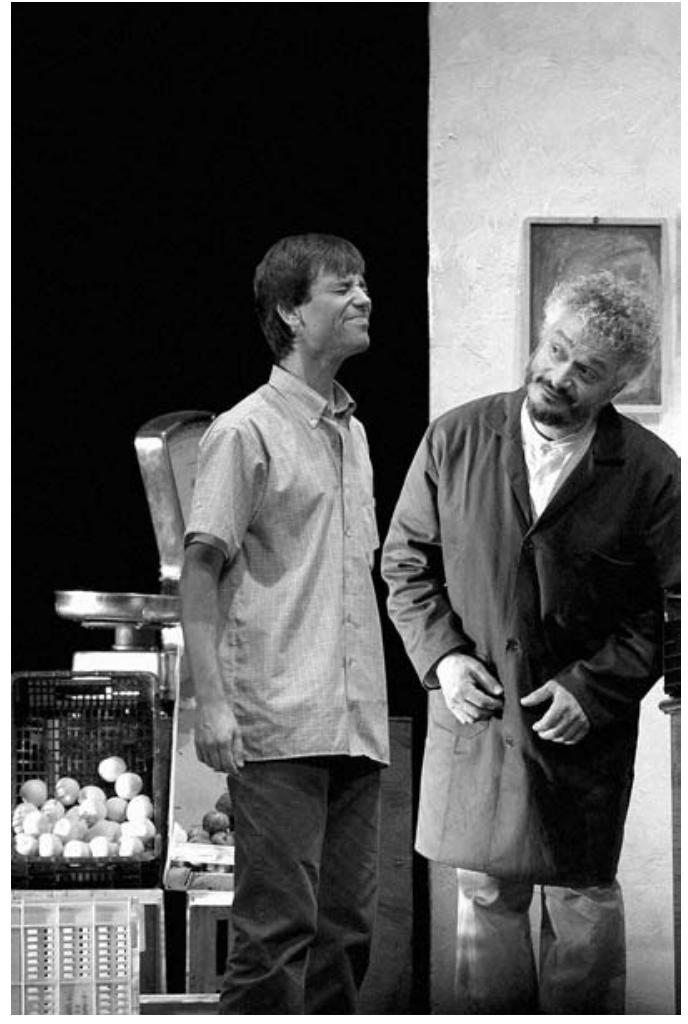

Uma narração bonita, que faz apelo aos bons sentimentos, à fraternidade e à solidariedade, contra os fanatismos, em defesa de valores autênticos, de final sereno. 0 velho irá deixar a vida sem remorsos nem rancores, porque teve uma boa vida e soube vivê-la. 0 rapaz tornar-se-á mais confiante e seguro, acolhendo a sua identidade cultural adquirida, e mestiça, de cabeça erguida. Momo receberá a herança humana e patrimonial de Ibrahim, de quem irá ocupar o lugar na loja, passando a ser para todos, inclusive para a mãe reintegrada na sua existência, o "árabe" do bairro. Porque essa loja está aberta das oito à meia-noite, domingos incluídos.

A realização cénica foi pouco elaborada, despretensiosa, de ilustração por vezes estereotipada, que se reflectiu também no registo imprimido na interpretação. Os actores Rui Damasceno (Ibrahim) e Hélder Wasterlain (Momo) caracterizaram as suas personagens de forma algo previsivel, mas não despicienda: um velho de voz grave e tom pausado, um jovem de aspecto tímido e posturas desajeitadas. 0 espaço cénico realisticamente pobre permitiu algum movimento devido às estantes giratórias que criavam sugestões de outros ambientes. Para medir o desenrolar do tempo e as mudanças de cenas, recorreuse ao baixar das luzes e à música de piano como fundo. Sem sobressaltos, nem rasgos de ousadia, esta produção foi porém muito digna e teve o mérito de reconciliar o espectador com um teatro humanista que não pode ser arredado dos palcos em nome de modas, ideologias ou experimentalismos de turno. Talvez procure ser complacente e agradar ao público, mas é por ideais que vale a pena preservar. 